Article

\title{
Modification of Montmorillonite with Polyethylene Oxide and Its Use as Support for $\mathbf{P d}^{\mathbf{0}}$ Nanoparticle Catalysts
}

\author{
Guiqing Shu, Jing Zhao, Xiu Zheng, Mengdie Xu, Qi Liu and Minfeng Zeng *(D) \\ Zhejiang Key Laboratory of Alternative Technologies for Fine Chemicals Process, College of Chemistry and \\ Chemical Engineering, Shaoxing University, Shaoxing 312000, China; guiqingshu@163.com (G.S.); \\ jingjingzhao218@sina.com (J.Z.); xiuzheng2019@163.com (X.Z.); joanne7280@163.com (M.X.); \\ lq920819@163.com (Q.L.) \\ * Correspondence: zengmf@usx.edu.cn; Tel.: +86-575-8834-1006
}

Received: 11 March 2019; Accepted: 18 April 2019; Published: 29 April 2019

check for updates

\begin{abstract}
In this study, montmorillonite (MMT) was modified by intercalating polyethylene oxide (PEO) macromolecules between the interlayer spaces in an MMT-water suspension system. X-ray diffraction results revealed that the galleries of MMT were expanded significantly after intercalation of different loading of PEO. MMT/PEO 80/20 composite was chosen as the support platform for immobilization of $\mathrm{Pd}$ species in preparing novel heterogeneous catalysts. After immobilization of Pd species, the interlayer spacing of MMT/PEO (80/20) (1.52 nm) was further increased to $1.72 \mathrm{~nm}\left(\mathrm{Pd}^{2+} @ \mathrm{MMT} / \mathrm{PEO}\right)$ and $1.73 \mathrm{~nm}\left(\mathrm{Pd}^{0} @ \mathrm{MMT} / \mathrm{PEO}\right)$, confirming the well-immobilization of the Pd species in the interlayer spaces of PEO-modified MMT. High-resolution transmission electron microscopy (HR-TEM) observation results confirmed that Pd nanoparticles were confined inside the interlayer space of MMT and/or dispersed well on the outer surface of MMT. The conversion of $\mathrm{Pd}^{2+}$ to $\mathrm{Pd}^{0}$ species was evidenced by binding energy characterization with $\mathrm{X}$-ray photo electron spectroscopy (XPS). The microstructure variation caused by the Pd immobilization was sensitively detected by positron annihilation lifetime spectroscopy (PALS) studies. The prepared $\mathrm{Pd}^{0} @ \mathrm{MMT} / \mathrm{PEO}(0.2 / 80 / 20)$ catalytic composite exhibits good thermal stability up to around $200^{\circ} \mathrm{C}$, and it showed high activities for Heck reactions between aryl iodides and butyl acrylates and could be recycled for five times. The correlations between the microstructure and properties of the Pd@MMT/PEO catalytic composites were discussed.
\end{abstract}

Keywords: polyethylene oxide; montmorillonite clays; Pd catalysis; catalytic composite; positron annihilation

\section{Introduction}

The modification of montmorillonite (MMT) with organic polymers has attracted more and more interests for their excellent structural and/or functional performances [1-3]. Many water-soluble polymers, such as polyethylene glycol (PEG) [4], polyethylene oxide (PEO) [5], polyvinyl alcohol (PVA) [6], polyvinyl pyrrolidone (PVP) [7], etc., can be easily intercalated in MMT with the water solution intercalation method. In the MMT/polymer nanocomposites, an obvious increase in the interlayer spacing of MMT is frequently observed, indicating the intercalated polymer chains are well-confined in the narrow galleries between the MMT layers. Meanwhile, the lipophilicity of MMT will be significantly improved after the organic polymer chains intercalated. The prepared MMT/polymer hybrid composites are nowadays frequently applied in many fields, such as preparation of advanced nano-composites, drug delivery, and water treatment, etc. [8-10]. 
Recently, many researchers shift the attentions towards heterogeneous catalysis topics with use of MMT-based composites [11-14]. In particular, MMT/polymer composites have been recognized as good supporting materials for immobilization of transition metal catalysts applied in organic reactions [15-21]. With synergetic processes of ion-exchange with interlayer cations of MMT and complexation with polar polymers, the transition metal cations, like $\mathrm{Pd}^{2+}$ will be easily immobilized on MMT/polymer supports. It has been evidenced that polymers (such as PVA, PVP, chitosan (CS), etc.) modified MMT supported Pd catalytic materials has good comprehensive catalytic performances as applied in Heck and/or Sonogashira coupling reactions. Pd species can be tightly encaged in the narrow galleries between the MMT layers. For same Heck reaction, it is reported $[15,17]$ that Pd@MMT/CS can reuse more times (30 times) than Pd@MMT/PVP catalysts (10 times). It was due to the weaker encaging of Pd species for bigger interlayer space formed in the case of Pd@MMT/PVP and lower chelation ability of PVP than that of CS. This revealed that the catalytic performances can be tailored with different kinds of polymers for the different intercalation structure formed and chelation ability with transition metals.

Polyethylene oxide is another well-known modifier for MMT and the prepared MMT/PEO hybrid composites show potential applications in many fields [22,23]. It was suggested that PEO chains could form single or double-ordered layer arrangements in the interlayer space of MMT. The ending groups of $\mathrm{PEO}$, i.e., $-\mathrm{OH}$ groups, have effective chelation capability with transition metal species. Also, $\mathrm{PEO}$ is known as an effective stabilizer for transition metal nanoparticles in reducing of their agglomeration to form big-sized particles [24,25]. PEO itself has been used as a polymer support for Pd catalysts in Heck reactions [26-28]. For example, PEO-supported recyclable NC palladacycle catalysts were developed by Karami and co-workers [28] by blending of dimeric NC palladacycle with PEO melts at $85^{\circ} \mathrm{C}$. However, the size of the prepared Pd nanoparticles is too large (bigger than $50 \mathrm{~nm}$ ) and it just showed moderate catalysis efficiency (up to $80 \%$ yield) for Heck reactions. Therefore, further modification of PEO-supported Pd catalysts is needed. It is expected that PEO-modified MMT should be another good candidate of support for immobilization of transition metals (such as Pd) in heterogeneous catalytic materials preparation.

In this study, PEO-modified MMT supports with different content and Pd-supported on MMT/PEO catalytic composites have been prepared. The microstructure of the PEO chains and Pd species confined in the interlayer space of MMT was characterized by several methods, including X-ray diffraction (XRD), high resolution transmission electron microscopy (HR-TEM), X-ray photo electron spectroscopy (XPS), thermal analysis, differential scanning calorimetry (DSC), and inductively coupled plasma-atomic emission spectroscopy (ICP). The sub-nano level microstructure of Pd@MMT/PEO catalytic composites was further studied by positron annihilation lifetime spectroscopy (PALS). The correlations between the microstructure and catalytic performances of Pd@MMT/PEO catalytic composite in Heck reactions were discussed.

\section{Materials and Methods}

\subsection{Materials}

$\mathrm{Na}^{+}-\mathrm{MMT}$ (G-105 type) of was purchased from Nanocor Co., Arlington Hts, IL, USA and its cationic exchange capacity was $145 \mathrm{mmol} / 100 \mathrm{~g}$. PEO $\left(M_{\mathrm{n}}=2 \times 10^{4} \mathrm{~g} / \mathrm{mol}\right)$ was purchased from Sinopharm Chemical Reagent Co., Ltd. Shanghai, China. $\mathrm{PdCl}_{2}$ (analytical grade) was purchased from Zhejiang Metallurgical Research Institute Co., Ltd. Hangzhou, China. The aromatic halides and acrylate substrates used in Heck reactions were purchased from Energy Chemical, Sun Chemical Technology (Shanghai) Co., Ltd. Shanghai, China. Other used reagents and solvents with no further treatments were purchased from Sinopharm Chemical Reagent Co., Ltd. Shanghai, China. 


\subsection{Sample Preparation}

A total of $100 \mathrm{~mL}$ of $2 \mathrm{wt} \%$ of MMT suspension solution was prepared under magnetic stirring. Specific amounts of PEO were dispersed in $100 \mathrm{~mL}$ of deionized water to form homogeneous solution. The PEO solution and the MMT suspension solution were mixed and kept magnetically stirred in water bath at $55^{\circ} \mathrm{C}$ for $12 \mathrm{~h}$. The mass ratios of MMT/PEO were set as 100/0, 90/10, 80/20, 70/30, 60/40, and 50/50. $0.3 \mathrm{~g}$ of $\mathrm{PdCl}_{2}$ was dissolved in $100 \mathrm{~mL}$ deionized water with the presence of excessive amounts of $\mathrm{NaCl}$ (about $2 \mathrm{~g}$ ). Then, $2 \mathrm{~mL}$ of the fresh $\mathrm{Pd}^{2+}$ solution was drop-wisely added into the above MMT/PEO (80/20) mixture and kept magnetically stirring for another $6 \mathrm{~h}$. The $\mathrm{Pd}^{2+} @ \mathrm{MMT} / \mathrm{PEO}$ composite was separated by centrifugation and washed with deionized water until neutral $(\mathrm{pH}=7)$. Afterwards, it was dried in an oven at $60^{\circ} \mathrm{C}$. The resultant $\mathrm{Pd}^{2+} @ \mathrm{MMT} / \mathrm{PEO}$ composite was reduced to $\mathrm{Pd}^{0} @ \mathrm{MMT} / \mathrm{PEO}$ with ethylene glycol at $80^{\circ} \mathrm{C}$. According to the ICP-AES determination results, the $\mathrm{Pd}$ content within the Pd@MMT/PEO catalytic composite was about $0.2 \mathrm{wt} \%$.

\subsection{Characterizations}

The characterization methods were similar to those in our recent works [19-21]. The XRD analysis of MMT/PEO and Pd@MMT/PEO samples were performed with a PANalytical Empyrean X-ray diffraction system (conditions: $2 \theta$ from $3^{\circ}$ to $70^{\circ}$, scanning rate of $2^{\circ} / \mathrm{min}$ ). The TGA and DSC curves of MMT/PEO and Pd@MMT/PEO samples were recorded with a Mettler Toledo TGA/DSC 2 STAR system (Zurich, Switzerland) (conditions: air atmosphere, from 30 to $700{ }^{\circ} \mathrm{C}$, scanning rate of $20^{\circ} \mathrm{C} / \mathrm{min}$ ). The XPS analysis of Pd@MMT/PEO sample was performed with a Thermo Fisher Scientific ESCALAB 250Xi X-ray photoelectron spectrometer. The Pd@MMT/PEO samples were embedded in epoxy resin and then microtomed for HRTEM observation, which was performed with a JEM-2100F HR-TEM (JEOL Ltd. Tokyo, Japan). The ICP determination of Pd@MMT/PEO samples were performed with a Leemann ICP-AES Prodigy XP inductively coupled plasma atomic emission spectrometry. The positron annihilation lifetime spectroscopy (PALS) analysis of MMT/PEO and Pd@MMT/PEO samples was performed with an EG \& G ORTEC fast-slow system (conditions: time resolution of 198 ps). Before PALS measuments, the MMT/PEO and Pd@MMT/PEO samples were pressed into disks (diameter $\times$ thickness: $1 \mathrm{~cm} \times 2 \mathrm{~mm}$ ) using a 769YP-15A powder tableting machine (Shanghai Xinnuo Instrument Ltd., Shanghai, China). During lifetime spectra measurements, the positron source $\left({ }^{22} \mathrm{NaCl}, 16 \mu \mathrm{Ci}\right.$, deposited between two Kapton foils) was sandwiched between two pre-pressed $\mathrm{Pd} @ \mathrm{MMT} / \mathrm{PEO}$ samples disks. The analysis of the positron annihilation spectra was performed with LT-9 (Lifetime-9) and MELT-4 (Maximum Entropy for Lifetime Analysis-4) programs.

\subsection{Catalytic Test}

In a $50 \mathrm{~mL}$ of round bottom flask reactor, a mixture of aromatic halide substrates $(1 \mathrm{mmol})$, acrylates substrates $(2 \mathrm{mmol}), \mathrm{Pd}^{0} @ \mathrm{MMT} / \mathrm{PEO}$ catalytic composite $(3 \mu \mathrm{mol}$ of $\mathrm{Pd}), \mathrm{CH}_{3} \mathrm{COOK}$ base ( $3 \mathrm{mmol}$ ), and solvent ( $5 \mathrm{~mL}$ DMSO $+0.2 \mathrm{~mL}$ ethylene glycol) was magnetically stirred at $110^{\circ} \mathrm{C}$ (oil bath heating) for $5 \mathrm{~h}$. The coupling reaction progress was detected with both layer chromatography (TLC) method and gas chromatography-mass spectrometry (GC/MS) analysis (Agilent 6890N/5975 MSD GC/MS, Palo Alto, CA, USA). The coupling reaction yield is according to the GC/MS quantitative analysis results of the reaction mixture. All the coupling products' chemical structure was confirmed by the analysis results of both $\mathrm{H}^{1}$ NMR and GC/MS, which was consistent with our recent works [21,29]. The recycling experiments of the Pd@MMT/PEO were performed as follows: firstly, filtration out the Pd@MMT/PEO from the reaction system; secondly, repeatedly washing of the filtrated Pd@MMT/PEO with ethanol for 3-5 times and drying; finally, putting the recycled Pd@MMT/PEO into the reaction mixture for use in next reaction run. 


\section{Results and Discussions}

Figure 1 shows the XRD patterns of MMT/PEO and Pd@MMT/PEO and the basal spacing $\left(d_{001}\right)$ value for the MMT estimated by Bragg's formula is summarized in Table 1. Meanwhile, when the thickness of the single layer of pure $\mathrm{Na}^{+}$-MMT $(0.96 \mathrm{~nm})$ is taken into account, the interlayer spacing of MMT can be estimated (also shown in Table 1). In the galleries between the MMT layers, the intercalated PEO chains would show different arrangements according to the interlayer spacing values and macromolecular configurations of PEO chains. For pure $\mathrm{Na}^{+}-\mathrm{MMT}$, the $d_{001}$ is $1.25 \mathrm{~nm}$, and its corresponding interlayer spacing is $0.29 \mathrm{~nm}$. At the MMT/PEO ratios of 90/10, the $d_{001}$ and interlayer spacing increases to $1.44 \mathrm{~nm}$ and $0.48 \mathrm{~nm}$, respectively. Some of previous works [23,30] showed that the intercalated PEO chains would be in helical conformation. However, it is worth noting that the size of PEO chains with a helical conformation is about $0.8 \mathrm{~nm}(>0.48 \mathrm{~nm})$. It indicates that the helical conformation of PEO chains in the interlayer space of MMT is not to be the case. Similar with recent work by Zhu et al. [31], lateral single layer of PEO chain with random conformation confined inside the galleries between the MMT layers in the case of MMT/PEO (90/10) might be much more possible. At the MMT/PEO ratios of $80 / 20$ and 70/30, the interlayer spacing shows a slow increase to $0.56 \mathrm{~nm}$ (MMT/PEO (80/20)) and $0.62 \mathrm{~nm}$ (MMT/PEO (70/30)), respectively. It should be a wider monolayer of PEG chain confined inside the galleries between the MMT layers. At the MMT/PEO ratios further increase to $60 / 40$ and 50/50, the interlayer spacing shows further increases to $0.85 \mathrm{~nm}$ (MMT/PEO 60/40) and 0.86 nm (MMT/PEO 50/50), indicating bilayers of PEO chains confined inside the galleries between the MMT layers. As we know, PEO is a polymer with high crystalline capability. One more layers highly-ordered arrangements should be beneficial to the formation of PEO crystals. The formation of crystal phase of PEO bulk would lead to a decrease in organic modification efficiency for MMT. Therefore, MMT/PEO (80/20) with wider monolayer arrangement was chosen as the platform for immobilization of $\mathrm{Pd}$ species in preparation of novel heterogeneous catalytic composites. The interlayer spacing of $\mathrm{Pd}^{2+} @ \mathrm{MMT} / \mathrm{PEO}(0.2 / 80 / 20)$ increases to $0.76 \mathrm{~nm}, 0.2 \mathrm{~nm}$ bigger than MMT/PEO (80/20). This confirms that the $\mathrm{Pd}^{2+}$ cations are effectively chelated by the PEO chains and well confined inside the galleries of MMT. Though the calculated mean interlayer spacing of $\mathrm{Pd}^{0} @ \mathrm{MMT} / \mathrm{PEO}(0.2 / 80 / 20)$ is close to $\mathrm{Pd}^{2+} @ \mathrm{MMT} / \mathrm{PEO}(0.2 / 80 / 20)$, the scattering peak from $\mathrm{Pd}^{0} @ \mathrm{MMT} / \mathrm{PEO}$ becomes a bit narrower. It is presumably caused by the local distortion of the layered structure by in-situ-generated $\mathrm{Pd}^{0}$ nanoparticles with uniform size.



Figure 1. XRD patterns of MMT/PEO hybrids and Pd@MMT/PEO catalytic composites. A. MMT; B. MMT/PEO (90/10); C. MMT/PEO (80/20); D. MMT/PEO (70/30); E. MMT/PEO (60/40); F. MMT/PEO (50/50); G. Pd ${ }^{2+} @$ MMT/PEO (0.2/80/20); H. Pd ${ }^{0} @$ MMT/PEO (0.2/80/20). 
Table 1. Results of $d_{001}$ spacing and corresponding interlayer spacing (subtracting the thickness of MMT layer of $0.96 \mathrm{~nm}$ ) of the investigated MMT from XRD.

\begin{tabular}{|c|c|c|c|}
\hline Sample & $2 \theta\left({ }^{\circ}\right)$ & $d_{001}$ Spacing $(\mathrm{nm})$ & Interlayer Spacing (nm) \\
\hline A. MMT & 7.02 & 1.25 & 0.29 \\
\hline B. MMT/PEO (90/10) & 6.15 & 1.44 & 0.48 \\
\hline C. MMT/PEO (80/20) & 5.78 & 1.52 & 0.56 \\
\hline D. MMT/PEO (70/30) & 5.60 & 1.58 & 0.62 \\
\hline E. MMT/PEO (60/40) & 4.88 & 1.81 & 0.85 \\
\hline F. MMT/PEO (50/50) & 4.84 & 1.82 & 0.86 \\
\hline G. Pd²+@MMT/PEO (0.2/80/20) & 5.13 & 1.72 & 0.76 \\
\hline H. Pd0@@MMT/PEO (0.2/80/20) & 5.11 & 1.73 & 0.77 \\
\hline
\end{tabular}

The microstructure of the Pd@MMT/PEO catalytic composite was further characterized with XPS and HR-TEM. As shown in Figure 2A, for Pd ${ }^{2+} @ \mathrm{MMT} / \mathrm{PEO}$, the binding energy peaks are found at $337.5 \mathrm{eV}\left(\mathrm{Pd}_{3} \mathrm{~d}_{5 / 2}\right)$ and $342.9 \mathrm{eV}\left(\mathrm{Pd}_{3} \mathrm{~d}_{3 / 2}\right)$, confirming the presences of $\mathrm{Pd}^{2+}$ species [32]. As shown in Figure $2 \mathrm{~B}$, for $\mathrm{Pd}^{0} @ \mathrm{MMT} / \mathrm{PEO}$, the binding energy peaks shift to $335.6 \mathrm{eV}\left(\mathrm{Pd}_{3 / 2}\right)$ and $340.9 \mathrm{eV}$ $\left(\mathrm{Pd}_{3} \mathrm{~d}_{3 / 2}\right)$, respectively, confirming the presences of $\mathrm{Pd}^{0}$ species [32]. Clearly, XPS characterization results supply a powerful evidence for the conversion of $\mathrm{Pd}^{2+}$ to $\mathrm{Pd}^{0}$. Figure 3 shows HR-TEM results of the MMT/PEO (80/20) hybrid and $\mathrm{Pd}^{0} @ \mathrm{MMT} / \mathrm{PEO}(0.2 / 80 / 20)$ catalytic composite. MMT/PEO (80/20) shows a typical layered structure with well-ordered parallel stacking of silicate MMT layers. For $\mathrm{Pd}^{0} @ \mathrm{MMT} / \mathrm{PEO}(0.2 / 80 / 20)$, it is observed that the interlayer contrast is much clearer than MMT/PEO (80/20). It should be due to the slight increase in the interlayer spacing after immobilization of $\mathrm{Pd}$ species, which is also evidenced by XRD characterization. Meanwhile, it is observed the dispersion states of $\mathrm{Pd}^{0}$ nanoparticles $(2-4 \mathrm{~nm})$ in the MMT/PEO (80/20) matrices are in two forms: (1) being confined inside 1-3 layers of MMT, (2) dispersed on the outer surface of MMT layers.
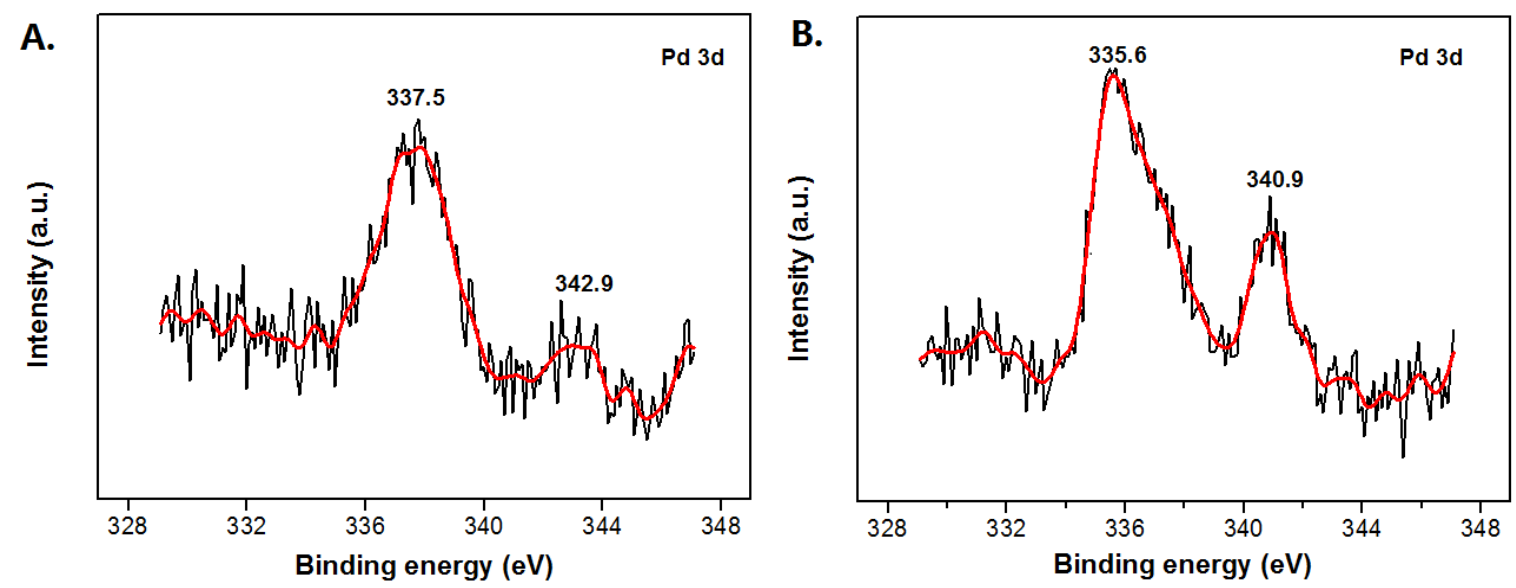

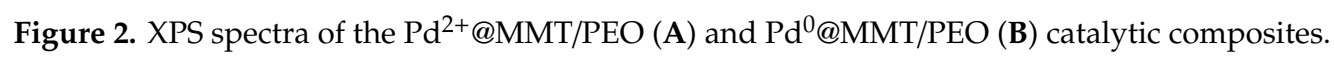





Figure 3. HR-TEM results of the MMT/PEO (80/20) hybrid (A) and $\mathrm{Pd}^{0} @ \mathrm{MMT} / \mathrm{PEO}(0.2 / 80 / 20)$ catalytic composite (B). The insert figures are the enlarged view of the local regions in the HR-TEM photos.

Meanwhile, the effects of the Pd immobilization on the molecular level microstructure of Pd@MMT/PEO catalytic composite have been characterized by PALS. The positron annihilation

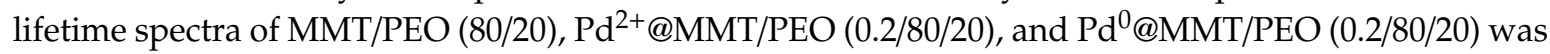
analyzed by three-component fitting using LT- 9 and MELT-4 programs. We mainly take attentions to the longest (third) lifetime component $\left(\tau_{3}\right)$, which is attributed to the ortho-positronium (o-Ps) annihilations inside the interlayer space of MMT [33-35]. The size of the micro defects can be estimated from $\tau_{3}$ with suitable models. It was evidenced that the modified Tao-Eldrup equation for cuboidal voids (Equation (1)) worked well for the MMT-based materials with layered structure [35-38]. Where, $l$ refers to the mean width of cuboidal micro defects, and $\Delta l(0.17 \mathrm{~nm})$ refers to the value of empirical parameter.

$$
\tau_{3}=0.5\left[1-\left(\frac{l}{l+2 \Delta l}+\frac{1}{\pi} \sin \frac{\pi l}{l+2 \Delta l}\right)\right]^{-1}
$$

The sizes of the micro defects estimated with Equation (1) are listed in Table 2. The PALS result of pure MMT sample has been reported in our recent work [20], the $o$-Ps lifetime is $2.801 \mathrm{~ns}$, and the mean micro defects size $(l)$ of MMT can be calculated as $0.3443 \mathrm{~nm}$. This value is bigger than that of MMT/PEO (80/20), $0.2901 \mathrm{~nm}$. This is due to the fact that the interlayer space of MMT becomes more crowded after the PEO chains intercalate. Meanwhile, the effects of the Pd immobilization and 
reducing treatment on the microstructure have been sensitively detected. Though the interlayer space is expanded obviously after $\mathrm{Pd}^{2+}$ immobilized as determined by $\mathrm{XRD}$, the mean micro defects size (l) show a decrease from $0.2901 \mathrm{~nm}(\mathrm{MMT} / \mathrm{PEO}(80 / 20))$ to $0.2792 \mathrm{~nm}\left(\mathrm{Pd}^{2+} @ \mathrm{MMT} / \mathrm{PEO}(0.2 / 80 / 20)\right)$. By forming effective chelation with $-\mathrm{OH}$ groups, $\mathrm{Pd}^{2+}$ cations play a role similar to cross-linking points for PEO chains, leading to a decrease in micro defects size within the intercalated PEO phase. $\mathrm{Pd}^{0}$ species often has poorer chelation capability with polar groups than $\mathrm{Pd}^{2+}$ species. Therefore, the micro defects size then undergoes an increase to $0.2886 \mathrm{~nm}$ for $\mathrm{Pd}^{0} @ \mathrm{MMT} / \mathrm{PEO}(0.2 / 80 / 20)$. Figure 4 shows the distribution of the longest lifetime $\left(\tau_{3}\right)$ and corresponding micro-defect's size $(l)$ of the samples as fitted with MELT-4 program. Similar variation trend of the distribution range of the micro-defect's size is found.

Table 2. Variation of longest lifetime, intensity, and mean size of micro-defects of the samples analyzed by LT-9 program.

\begin{tabular}{cccc}
\hline Samples & $\boldsymbol{\tau}_{\mathbf{3}}$ (ns) & $\boldsymbol{I}_{\mathbf{3}} \mathbf{( \% )}$ & $\boldsymbol{l} \mathbf{( n m )}$ \\
\hline MMT/PEO (80/20) & 2.235 & 5.8 & 0.2901 \\
$\mathrm{Pd}^{2+} @ \mathrm{MMT} / \mathrm{PEO}(0.2 / 80 / 20)$ & 2.132 & 3.7 & 0.2792 \\
$\mathrm{Pd}^{0} @ \mathrm{MMT} / \mathrm{PEO}(0.2 / 80 / 20)$ & 2.220 & 4.5 & 0.2886 \\
\hline
\end{tabular}
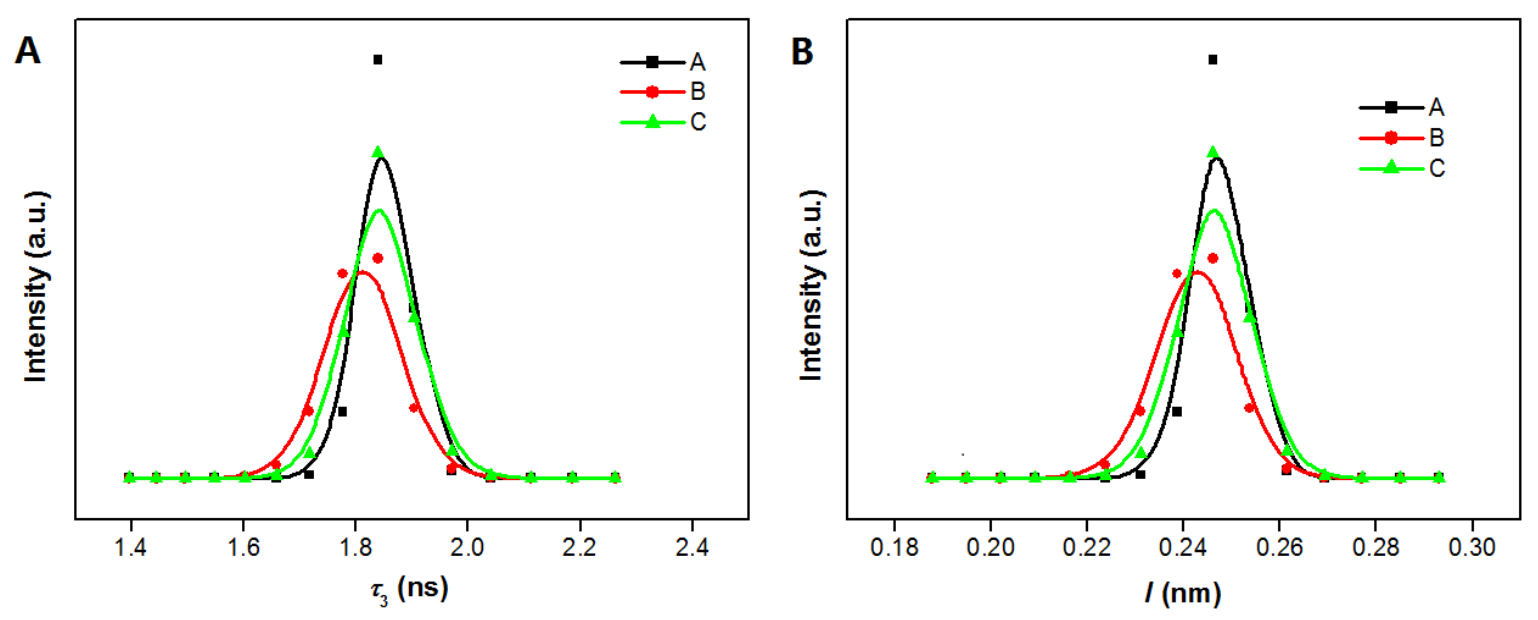

Figure 4. Distribution of the longest lifetime $\left(\tau_{3}\right)(\mathbf{A})$ and corresponding micro-defect's size $(l)(\mathbf{B})$ of the samples analyzed by MELT-4 program. A. MMT/PEO (80/20); B. Pd²+@MMT/PEO (0.2/80/20); C. Pd0 @MMT/PEO (0.2/80/20).

Figure 5A shows the TGA/DTG results of MMT/PEO hybrids and Pd0@MMT/PEO (0.2/80/20) catalytic composite. As a stable inorganic layered silicate mineral, MMT shows high thermal stability except a weight loss stage caused by the evaporation of absorbed and/or bonded $\mathrm{H}_{2} \mathrm{O}$ before $125^{\circ} \mathrm{C}$. The decomposition temperature (peak temperature of the DTA curve) of PEO is found at about $320^{\circ} \mathrm{C}$. For the MMT/PEO hybrids, decomposition temperature of PEO component shows an obviously decrease to $240{ }^{\circ} \mathrm{C}$ for MMT/PEO (80/20) and $200^{\circ} \mathrm{C}$ for MMT/PEO (60/40), respectively. This decrease should be due to the different aggregation states of $\mathrm{PEO}$ chains between pure PEO and MMT/PEO hybrid. Due to the high crystallization ability, most PEO chains tend to be regularly aggregated to form perfect crystals. As confirmed with DSC curves in Figure 5B, an endothermic peak of PEO crystal at $73^{\circ} \mathrm{C}$ is observed. However, as confined in the narrow galleries of MMT, PEO chains have much lower probabilities in regular aggregation to form crystals. Therefore, no obvious endothermic peak has been detected for the MMT/PEO hybrids and Pd $@$ MMT/PEO (0.2/80/20) catalytic composite. Usually, the formation of perfect crystal of PEO chains is advantageous for higher thermal stability. As a result, PEO component in MMT/PEO hybrids shows lower thermal decomposition temperature in TGA curves. The thermal decomposition temperature of $\mathrm{Pd}^{0} @ \mathrm{MMT} / \mathrm{PEO}(0.2 / 80 / 20)$ catalytic composite is 
close to MMT/PEO (80/20), indicating similar thermal stabilities. Clearly, the prepared $\mathrm{Pd}^{0} @ \mathrm{MMT} / \mathrm{PEO}$ $(0.2 / 80 / 20)$ catalytic composite could be adaptable in organic reactions below $200{ }^{\circ} \mathrm{C}$.
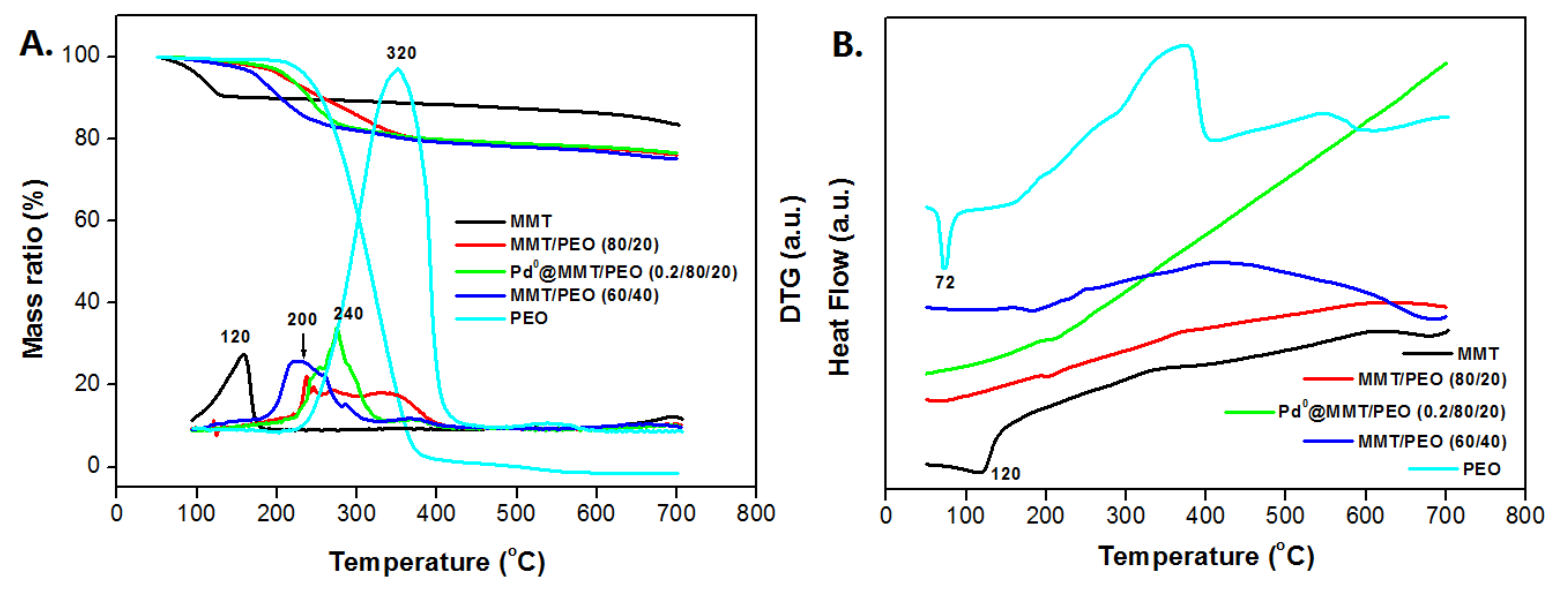

Figure 5. TGA/DTG (A) and DSC (B) curves of the MMT/PEO hybrids and Pd@MMT/PEO catalytic composite.

Heck reactions between aryl halides and butyl acrylate were catalyzed with the prepared $\mathrm{Pd}^{0} @ \mathrm{MMT} / \mathrm{PEO}$ catalytic composite. As shown in Table 3, the Pd $\mathrm{Pd}^{0} @ \mathrm{MMT} / \mathrm{PEO}$ catalytic composite shows high catalytic activity for the reaction between iodo benzene and $n$-butyl acrylate (entry $1,91 \%$ yield). It still exhibits high catalytic activity for aryl iodides substituted with either an electron-donating group, such as $p-\mathrm{CH}_{3}$ (entry $2,89 \%$ yield) and $m-\mathrm{CH}_{3} \mathrm{O}$ (entry $3,84 \%$ yield), or an electron-absorbing group (such as $p$-F (entry $4,88 \%$ yield), $m$-F (entry $5,87 \%$ yield). Heck reaction between aryl iodides and t-butyl acrylate can be also effectively catalyzed with the prepared $\mathrm{Pd}^{0} @ \mathrm{MMT} / \mathrm{PEO}$ catalytic composite (entry 6-8). The $\mathrm{Pd}^{0} @ \mathrm{MMT} / \mathrm{PEO}$ catalytic composite show low catalytic activity for the reaction between bromo benzene and $n$-butyl acrylate (entry 9 ), which is mainly due to the much higher bonding strength of C-Br than C-I to break. Nevertheless, C-Br bond can be activated by substitution of strong electron-absorbing group such as $m-\mathrm{COCH}_{3}$ (entry 10). Clearly, the catalytic activity of $\mathrm{Pd}^{0} @ \mathrm{MMT} / \mathrm{PEO}$ is much higher than PEO-supported recyclable NC palladacycle catalysts [28]. And it is also comparable to recent other reported heterogeneous catalysts for Heck reactions [39,40]. After the reaction, the $\mathrm{Pd}^{0} @ \mathrm{MMT} / \mathrm{PEO}$ catalytic composite can be conveniently separated and recycled for the next run. As shown in Figure 6, the catalytic efficiency of the $\mathrm{Pd}^{0} @ \mathrm{MMT} / \mathrm{PEO}$ catalytic composite decrease gradually as the recycling times increase. Similarly, higher recyclability is observed for the $\mathrm{Pd}^{0} @ \mathrm{MMT} / \mathrm{PEO}$ catalytic composite as compared with PEO-supported recyclable NC palladacycle catalysts (can recycle 4 times with moderate yield) [28]. However, it is obviously lower than recent prepared Pd $\mathrm{Pd}^{0} \mathrm{MMT} / \mathrm{PVA}$ or Pd $\mathrm{d}^{0} @ \mathrm{MMT} / \mathrm{PVP}$ catalysts $[19,20]$. For PEO, the polar $-\mathrm{OH}$ groups are distributed in the ending of the chain rather than each repeating unit of the chain like PVA. Reasonably weaker chelation and quicker Pd leaching will occur in the case of $\mathrm{Pd}^{0} @ \mathrm{MMT} / \mathrm{PEO}$. 
Table 3. Catalytic performances of $\mathrm{Pd}^{0} @ \mathrm{MMT} / \mathrm{PEO}$ for Heck reactions between aromatic halides with acrylates.

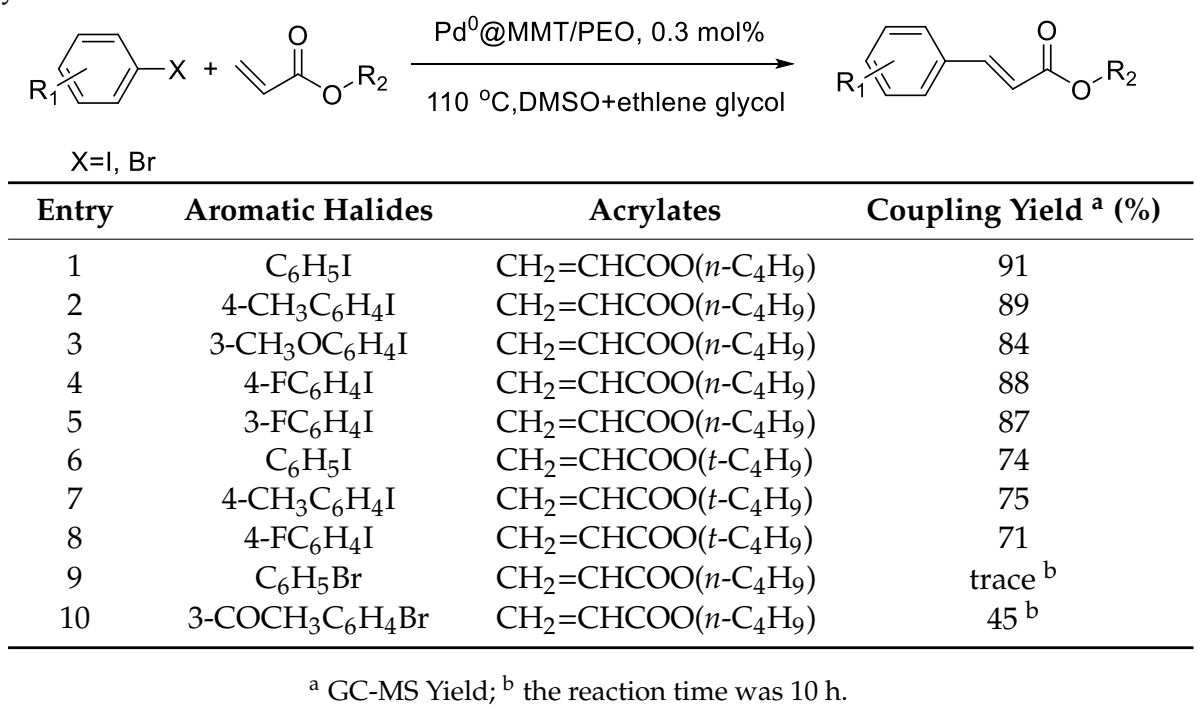

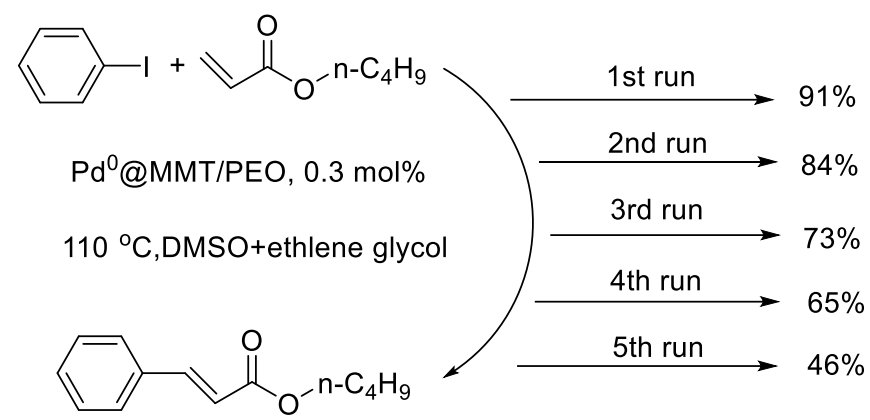

Figure 6. Recycling performances of the $\mathrm{Pd}^{0} @ \mathrm{MMT} / \mathrm{PEO}$ catalytic composites.

\section{Conclusions}

In this study, PEO chains were successfully intercalated into interlayer spaces of $\mathrm{Na}^{+}-\mathrm{MMT}$, which can be used as a novel support for $\mathrm{Pd}^{0}$ nanoparticles. $\mathrm{PEO}$ chains and $\mathrm{Pd}$ species are well confined in the interlayer space of MMT, which is well elucidated by XRD, HR-TEM, XPS, TGA, and PALS. It was demonstrated that $\mathrm{Pd}^{0}$ nanoparticles sized in $2-4 \mathrm{~nm}$ were successfully immobilized on MMT/PEO supports. The sub-nano level micro defects variation of MMT can be sensitively detected by PALS. After PEO intercalation and Pd immobilization, the micro defects undergo a slight decrease in size, which is mainly due to the fact that the interlayer space of MMT becomes more crowded. The prepared $\mathrm{Pd}^{0} @ \mathrm{MMT} / \mathrm{PEO}$ catalytic composite shows high catalytic activities for Heck reactions and can be recycled for five times. The lower recyclability of the $\mathrm{Pd}^{0} @ \mathrm{MMT} / \mathrm{PEO}$ than other reported $\mathrm{Pd}^{0} @ \mathrm{MMT} /$ polar polymers catalytic composites should be mainly due to the weaker chelation of PEO with Pd. Nevertheless, the comprehensive catalytic performances of the Pd0@MMT/PEO are much improved as compared with Pd heterogeneous catalysts which are prepared by directly supporting of Pd species on PEO chains. This work supplies an alternative approach in the preparation of $\mathrm{Pd}$ heterogeneous catalysts with fairly good performances, and might have broad prospects in both experimental and industrial applications.

Author Contributions: M.Z. conceived and designed the experiments; G.S., J.Z., and M.X. performed the materials preparation and characterization experiments; X.Z. and Q.L., performed the catalysis experiments.

Funding: This research was funded by the National Natural Science Foundation of China (Grant No. 11875193 and 11475114), Zhejiang Provincial Fundamental Public Welfare Research Project (Grant No. LGG18E030004), and University Students' Science and Technology Innovation Activity Plan Project of Zhejiang Province (Grant No. 2018R432012). 
Acknowledgments: We are grateful to the Xingzhong Cao and Baoyi Wang (Institute of High Energy Physics, The Chinese Academy of Science, China) for the positron annihilation characterization supports.

Conflicts of Interest: The authors declare no conflict of interest.

\section{References}

1. LeBaron, P.C.; Wang, Z.; Pinnavaia, T.J. Polymer-layered silicate nanocomposites: An overview. Appl. Clay Sci. 1999, 15, 11-29. [CrossRef]

2. Pavlidou, S.; Papaspyrides, C.D. A review on polymer-layered silicate nanocomposites. Prog. Polym. Sci. 2008, 33, 1119-1198. [CrossRef]

3. Bee, S.L.; Abdullah, M.A.A.; Bee, S.T.; Sin, L.T.; Rahmat, A.R. Polymer nanocomposites based on silylated-montmorillonite: A review. Prog. Polym. Sci. 2018, 85, 57-82. [CrossRef]

4. Zampori, L.; Dotelli, G.; Stampino, P.G.; Cristiani, C.; Zorzi, F.; Finocchio, E. Thermal characterization of a montmorillonite, modified with polyethylene-glycols (PEG1500 and PEG4000), by in situ HT-XRD and FT IR: Formation of a high-temperature phase. Appl. Clay Sci. 2012, 59-60, 140-147. [CrossRef]

5. Shen, Z.Q.; Simon, G.P.; Cheng, Y.-B. Comparison of solution intercalation and melt intercalation of polymer-clay nanocomposites. Polymer 2002, 43, 4251-4260. [CrossRef]

6. Strawhecker, K.E.; Manias, E. Structure and properties of poly (vinyl alcohol)/ $/ \mathrm{Na}^{+}$montmorillonite nanocomposites. Chem. Mater. 2000, 12, 2943-2949. [CrossRef]

7. Papp, S.; Patakfalvi, R.; Dekany, I. Metal nanoparticle formation on layer silicate lamellae. Colloid Polym. Sci. 2008, 286, 3-14. [CrossRef]

8. Paul, D.R.; Robeson, L.M. Polymer nanotechnology: Nanocomposites. Polymer 2008, 49, 3187-3204. [CrossRef]

9. Meirelles, L.M.A.; Raffin, F.N. Clay and polymer-based composites applied to drug release: A scientific and technological prospection. J. Pharm. Pharm. Sci. 2017, 20, 115-134. [CrossRef] [PubMed]

10. Floody, M.C.; Theng, B.K.G.; Reyes, P.; Mora, M.L. Natural nanoclays: Applications and future trends-chilean perspective. Clay Miner. 2009, 44, 161-176. [CrossRef]

11. Zhou, C.H. An overview on strategies towards clay-based designer catalysts for green and sustainable catalysis. Appl. Clay Sci. 2011, 53, 87-96. [CrossRef]

12. Kumar, B.S.; Dhakshinamoorthy, A.; Pitchumani, K. K10 montmorillonite clays as environmentally benign catalysts for organic reactions. Catal. Sci. Technol. 2014, 4, 2378-2396. [CrossRef]

13. Hechelski, M.; Ghinet, A.; Louvel, B.; Dufrenoy, P.; Rigo, B.; Daich, A.; Waterlot, C. From conventional lewis acids to heterogeneous montmorillonite K10: Eco-friendly plant-based catalysts used as green lewis acids. ChemSusChem 2018, 11, 1249-1277. [CrossRef] [PubMed]

14. Nasrollahzadeh, M.; Atarod, M.; Alizadeh, M.; Hatamifard, A.; Sajadi, S.M. Recent advances in the application of heterogeneous nanocaalysts for Sonogashira coupling reactions. Curr. Org. Chem. 2017, 21, 708-749. [CrossRef]

15. Heirati, S.Z.D.; Shirini, F.; Shojaei, A.F. Sulfonated PEG-intercalated montmorillonite [(Mt/PEG)-SO3H] as efficient and ecofriendly nanocatalyst for synthesis of alpha, alpha'-bis(substituted benzylidene) cycloalkanones. Res. Chem. Intermediat. 2017, 43, 6167-6186. [CrossRef]

16. Kar, P.; Nayak, A.; Bhoi, Y.P.; Mishra, B.G. Preparation and catalytic application of sulfonated PVA-Zr-pillared clay nanocomposite materials towards one pot synthesis of hexahydropyrimidines. Microporous Mesoporous Mater. 2016, 223, 176-186. [CrossRef]

17. Senarathna, K.G.C.; Randiligama, H.M.S.P.; Rajapakse, R.M.G. Preparation, characterization and oxygen reduction catalytic activities of nanocomposites of $\mathrm{Co}(\mathrm{II}) /$ montmorillonite containing polypyrrole, polyaniline or poly(ethylenedioxythiophene). RSC Adv. 2016, 6, 112853-112863. [CrossRef]

18. Li, T.; Sun, Y.L.; Zhou, R.; Long, M.D.; Liu, Y.F. Fabrication and application of porous Pd@Mt/PC composite as an efficient green heterogeneous catalyst for Suzuki cross-coupling reaction. Micro Nano Lett. 2018, 13, 969-973.

19. Xu, M.D.; Zhao, J.; Shu, G.Q.; Liu, Q.; Zeng, M.F. Heterogeneous catalytic composites from palladium nanoparticles in montmorillonite intercalated with poly (vinyl pyrrolidone) chains. Polymers 2018, 10, 669. [CrossRef]

20. Zhao, J.; Xu, M.D.; Shu, G.Q.; Yang, Z.; Liu, Q.; Zeng, M.F.; Qi, C.Z.; Cao, X.Z.; Wang, B.Y. Positron annihilation characteristics and catalytic performances of poly (vinyl alcohol) intercalated montmorillonite supported $\mathrm{Pd}^{0}$ nanoparticles composites. Radiat. Phys.Chem. 2018, 153, 164-172. [CrossRef] 
21. Zeng, M.F.; Wang, Y.D.; Liu, Q.; Yuan, X.; Zuo, S.F.; Feng, R.K.; Yang, J.; Wang, B.Y.; Qi, C.Z.; Lin, Y. Encaging palladium nanoparticles in chitosan modified montmorillonite for efficient, recyclable catalysts. ACS Appl. Mater. Interfaces 2016, 8, 33157-33164. [CrossRef]

22. Zampori, L.; Stampino, P.G.; Cristiani, C.; Cazzola, P.; Dotelli, G. Intercalation of poly (ethylene-oxides) in montmorillonite: Tailor-made nanocontainers for drug delivery systems. Appl. Clay Sci. 2010, 50, 266-270. [CrossRef]

23. Aranda, P.; Ruiz-Hitzky, E. Poly (ethylene oxide)-silicate intercalation materials. Chem. Mater. 1992, 4, 1395-1403. [CrossRef]

24. Doherty, S.; Knight, J.G.; Backhouse, T.; Abood, E.; Alshaikh, H.; Clemmet, A.R.; Ellison, J.R.; Bourne, R.A.; Chamberlain, T.W.; Stones, R.; Warren, N.J.; Fairlamb, I.J.S.; Lovelock, K.R.J. Heteroatom donor-decorated polymer-immobilized ionic liquid stabilized palladium nanoparticles: efficient catalysts for room-temperature Suzuki-Miyaura cross-coupling in aqueous media. Adv. Syn. Catal. 2018, 360, 3716-3731. [CrossRef]

25. Zharmagambetova, A.K.; Zamanbekova, A.T.; Darmenbayeva, A.S.; Auyezkhanova, A.S.; Jumekeyeva, A.I.; Talgatov, E.T. Effect of polymers on the formation of nanosized palladium catalysts and their activity and selectivity in the hydrogenation of acetylenic alcohols. Theor. Exp. Chem. 2017, 53, 265-269. [CrossRef]

26. Pires, M.J.D.; Purifição, S.I.; Santos, A.S.; Marques, M.M.B. The role of PEG on Pd- and Cu-catalyzed cross-coupling reactions. Synthesis 2017, 49, 2337-2350.

27. Iranpoor, N.; Firouzabadi, H.; Riazi, A.; Shakerpoor, A. Phosphorylated PEG (PPEG) as a new support for generation of nano-Pd(0): Application to the Heck-Mizoroki and Suzuki-Miyaura coupling reactions. Appl. Organomet. Chem. 2013, 27, 451-458. [CrossRef]

28. Karami, K.; Moghadam, Z.K.; Hosseini-Kharat, M. Polyethylene glycol-supported recyclable NC palladacycle catalyst for Heck cross-coupling reactions. Catal. Commun. 2014, 43, 25-28. [CrossRef]

29. Zeng, M.F.; Qi, C.Z.; Yang, J.; Wang, B.Y.; Zhang, X.-M. A highly efficient and stable palladium catalyst entrapped within the cross-linked chitosan membrane for Heck reactions. Ind. Eng. Chem. Res. 2014, 53, 10041-10050. [CrossRef]

30. Ruiz-Hitzky, E.; Aranda, P. Polymer-salt intercalation complexes in layer silicates. Adv. Mater. 1990, 2, 545-547. [CrossRef]

31. Zhu, S.P.; Chen, J.Y.; Li, H.L.; Cao, Y. Structure and conformation of poly(ethylene glycol) in confined space of montmorillonite. Appl. Surf. Sci. 2013, 264, 500-506. [CrossRef]

32. Wagner, C.D.; Riggs, W.M.; Davis, L.E.; Mullenberg, G.E. Handbook of X-ray Photoelectron Spectroscopy; Perkin-Elmer: Waltham, MN, USA, 1979.

33. Joshi, J.M.; Sodaye, H.S.; Pujari, P.K.; Srisaila, S.; Bajpai, M.B. Positron annihilation spectroscopic investigation of Al-pillared montmorillonites. Catal. Lett. 1998, 51, 109-112. [CrossRef]

34. Sano, M.; Murakami, H.; Ichimura, K. Positronium in a layered-structure material: Montmorillonite. J. Radioanal. Nucl. Chem. 1999, 239, 325-328. [CrossRef]

35. Consolati, G.; Natali-Sora, I.; Pelosato, R.; Quasso, F. Investigation of cation-exchanged montmorillonites by combined X-ray diffraction and positron annihilation lifetime spectroscopy. J. Appl. Phys. 2002, 91, 1928-1932. [CrossRef]

36. Jasińska, B.; Koziol, A.E.; Goworek, T. Voids shape and o-Ps lifetime in molecular crystals. Acta Phys. Pol. A 1999, 95, 557-561. [CrossRef]

37. Tao, S.J. Positronium annihilation in molecular substances. J. Chem. Phys. 1972, 56, 5499-5510. [CrossRef]

38. Eldrup, M.; Lightbody, D.; Sherwood, J.N. The temperature-dependence of positron lifetimes in solid pivalic acid. Chem. Phys. 1981, 63, 51-58. [CrossRef]

39. Bradshaw, M.; Zou, J.L.; Byrne, L.; Iyer, K.S.; Stewart, S.G.; Raston, C.L. Pd(II) conjugated chitosan nanofibre mats for application in Heck cross-coupling reactions. Chem. Commun. 2011, 47, 12292-12294. [CrossRef] [PubMed]

40. Zhan, K.; You, H.H.; Liu, W.Y.; Lu, J.; Lu, P.; Dong, J. Pd nanoparticles encaged in nanoporous interpenetrating polymer networks: A robust recyclable catalyst for Heck reactions. React. Funct. Polym. 2011, 71, 756-765. [CrossRef]

(C) 2019 by the authors. Licensee MDPI, Basel, Switzerland. This article is an open access article distributed under the terms and conditions of the Creative Commons Attribution (CC BY) license (http://creativecommons.org/licenses/by/4.0/). 